\title{
Prolonged manometric recording of anorectal motor activity in ambulant human subjects: evidence of periodic activity
}

\author{
D KUMAR, N S Williams, D WALDRON, AND D L WINGATE \\ From the Surgical and GI Science Research Units, London Hospital Medical College, London
}

SUMMARY Based on short recordings, the rectum has been shown to have contractions with a frequency of five to 10 cycles per minute and slow contractions at three cycles per minute. To define anorectal motility over a prolonged period of time, we have studied 12 healthy volunteers using a fine pressure sensitive anorectal probe. A total of 240 hours of recording was obtained. We observed three types of activity in the rectum: (i) runs of powerful phasic contractions with a frequency of two to three per minute, lasting for three to 10 minutes, and recurring to an interval of $92(1.9)$ minutes (mean (SEM)) during the day and $56(1 \cdot 7)$ minutes (mean (SEM)) at night, (ii) isolated prolonged contractions lasting for 10-20 seconds and seen mainly during waking, and (iii) clusters of contractions occurring at a frequency of five to six per minute lasting for one to two minutes and seen predominantly during the postprandial period. These clusters of contractions resembled the discrete clustered contractions seen in the ileum, whereas the more powerful and prolonged runs of contractions resembled phase III activity in the small intestine. In contrast, the anal canal showed bursts of contractions which were not temporally related. Our data show that the rectum, like the upper gastrointestinal tract, exhibits periodic motor activity; it remains to be seen whether these two biorhythms are synchronous.

The interdigestive migrating motor complex (MMC) and its electrical equivalent, the myelectric complex, have been shown to migrate cyclically through the small bowel of many species, including man. ${ }^{1-6}$ Most studies in man, aimed at investigating the cyclical nature of gastrointestinal motility, have been confined to the upper small bowel; few have studied the ileum and proximal colon. ${ }^{6}$ Anorectal studies have largely confined themselves to the measurement of resting and squeeze pressure and the study of rectoanal reflexes. The possibility that the human anorectum exhibits periodic activity has not been investigated.

Water filled catheters, water or air filled balloons, sleeve catheters and force transducers have all been used to measure contractile activity in the anorectum; conflicting results have been reported. ${ }^{7-10}$ The rectum has been described as being quiescent

Address for correspondence: Dr D Kumar, Surgical Unit, London Hospital, Whitechapel, London E1 1BB.

Accepted for publication 23 November 1988. most of the time with a basal pressure of about $5 \mathrm{~cm}$ $\mathrm{H}_{2} \mathrm{O}$. Three main types of contractile activity have been described in the rectum; (i) simple contractions occurring at a frequency of 5-10 cycles per minute, (ii) slower contractions at a frequency of 3 cycles per minute, and (iii) 'slow' propagated contractions. ${ }^{11} 12$ All the current knowledge of anorectal motility is based on short recordings in a laboratory setting. Such techniques will not detect diurnal variations, or periodic activity. The object of this study was to record anorectal motor activity for prolonged periods in ambulant human subjects.

Methods

SUBJECTS

We have studied 12 healthy volunteers (seven men, aged 18-55 years). All subjects gave informed consent and none gave a history of previous gastrointestinal symptoms, anorectal surgery or use of pharmaceutical agents which could influence anorectal function. Female volunteers were allowed 
to take the contraceptive pill. No bowel preparation was undertaken before the study.

\section{Recording technique}

Pressure was measured using a flexible probe with an external diameter of $2 \mathrm{~mm}$, incorporating two pressure sensitive strain gauge transducers spaced $10 \mathrm{~cm}$ apart. The probe is connected to a miniature battery operated interface unit $(14 \times 7 \times 3 \mathrm{~cm})$ powered by a 9V PP3 alkaline dry cell. This unit contains the strain gauge amplifiers, and the signal encoding circuitry. Pulse interval modulation ${ }^{13}$ is used to encode the data; the strain gauges are activated for $1 \mathrm{msec}$ at intervals of $35-55 \mathrm{msec}$. The interval between the pulses is proportional to the pressure exerted on the strain gauge, and thus the pressure data are encoded in a pulse train that is recorded on magnetic tape on the attached data logging cassette tape recorder (Medilog 4-24, Oxford Medical Systems, Abingdon, Oxon). A time signal with a one minute marker is automatically included on the magnetic tape.

At the end of the study, the probe is withdrawn from the subject. The magnetic tape is replayed through decoding circuitry ${ }^{14}$ so as to produce an analogue record on a chart recorder (Gould RS

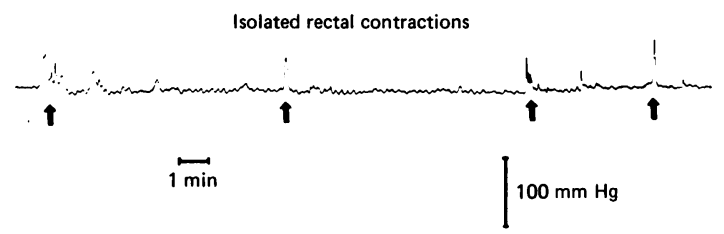

Fig. 1 Manometric record from the rectum of a healthy volunteer showing prolonged and isolated rectal contractions (arrows).
3400). Comparison of the graphic record with the patients' diary and with the time signal which is displayed during tape replay allows motor events to be correlated with relevant activity (feeding, sleep, etc) by the patient during the study. Movement artefacts were identified as simultaneous events occurring at both channels and were excluded from the analysis.

\section{Experimental design}

Subjects were asked to report to the clinical study unit between 0800 and 1000 hours on the first day. Subjects were encouraged to defecate (if possible) before the commencement of the study. The probe was introduced through the anus and positioned so that the proximal sensor was located in the rectum and the distal sensor in the midanal canal $(1.5-2 \mathrm{~cm}$ from the anal verge). Subjects were asked to report immediately if the probe was expelled on defecation during the study so that it could be repositioned. During the study, subjects were ambulant, ate regular meals, and were able to sleep at home. All subjects kept a diary of meals consumed, time of going to bed, and any strenuous activity undertaken during the study.

STATISTICAL ANALYSIS

Student's $t$ test was used for statistical analysis.

\section{Results}

The manometry probe was easy to use and was well tolerated by the subjects. No adverse effects were reported by any of the volunteers. A total of 240 hours of recording was obtained (mean of 20 hours of recording per subject). The position of the sensors was checked at the end of each study. There was no displacement of the probe in any of our subjects. One
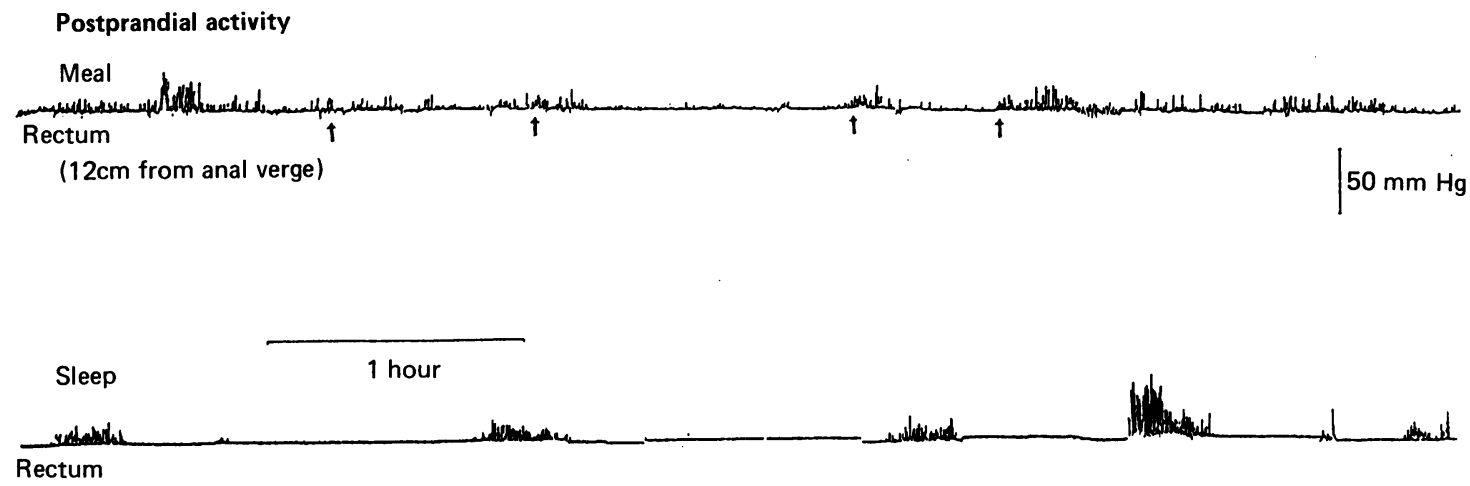

Fig. 2 Continuous record from the rectum of a healthy subject. The top trace shows the effect of a meal on rectal motility. Note the clusters of contractions (arrows) in the postprandial period. The lower trace shows RMCs during sleep. 

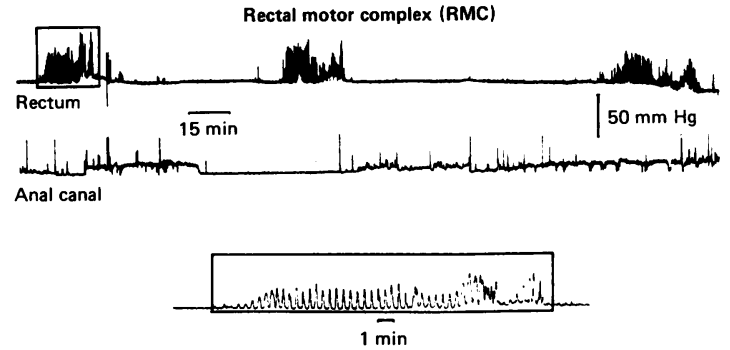

Fig. 3 Example of RMCs in a healthy volunteer. The inset shows an RMC at a faster speed. Note the regular and sustained nature of contractions in comparison with the isolated rectal contractions shown in Figure 1.

subject managed to expel the probe on defecation during the study. It was repositioned and stayed in position for the rest of the study. Taping the probe close to the anal verge secured the position of the sensors and prevented their displacement in all subjects. All subjects ate regular meals and slept at home.

\section{RECTUM}

Three types of motor activity were seen in the rectum: (i) Isolated prolonged contractions lasting for 10-20 seconds and seen mainly during waking (Fig. 1). (ii) Clusters of contractions of relatively low amplitude at a frequency of five to six per minute (Fig. 2). These clusters lasted for one to two minutes, recurred at 20-30 minute intervals and were seen predominantly in the postprandial period. These were not associated with a feeling of rectal fullness or urge to defecate. (iii) Runs of powerful $(>50 \mathrm{mmHg})$ contractions (Fig. 3) with a dominant frequency of three cycles per minute (range $2-3$ cycles per minute) and sustained for three to 10 minutes recurring at a mean interval of $92(1.9)$ minutes during the day (mean (SEM)) and 56 (1.7) minutes (mean (SEM)) at night. These closely resembled the phase III contractions of the migrating motor complex (MMC) in the small bowel.

The periodic activity in the rectum was disrupted by food in all the subjects in our study (Fig. 2). The postprandial activity lasted for 185 (45) minutes (mean (SD)) and consisted of either clustered low amplitude contractions or irregular contractions. These were of lower amplitude than the RMCs.

During nocturnal sleep, the periodic bursts of powerful contractions were more regular and occurred with a periodicity of $56(1.7)$ minutes (mean (SEM)) (Fig. 4). The cycle length of these phase IIIlike contractions was significantly shorter $(p<0.001)$ at night (Table). Unlike phase III of small bowel MMC there was no transitional phase (phase II) between quiescence and RMCs.

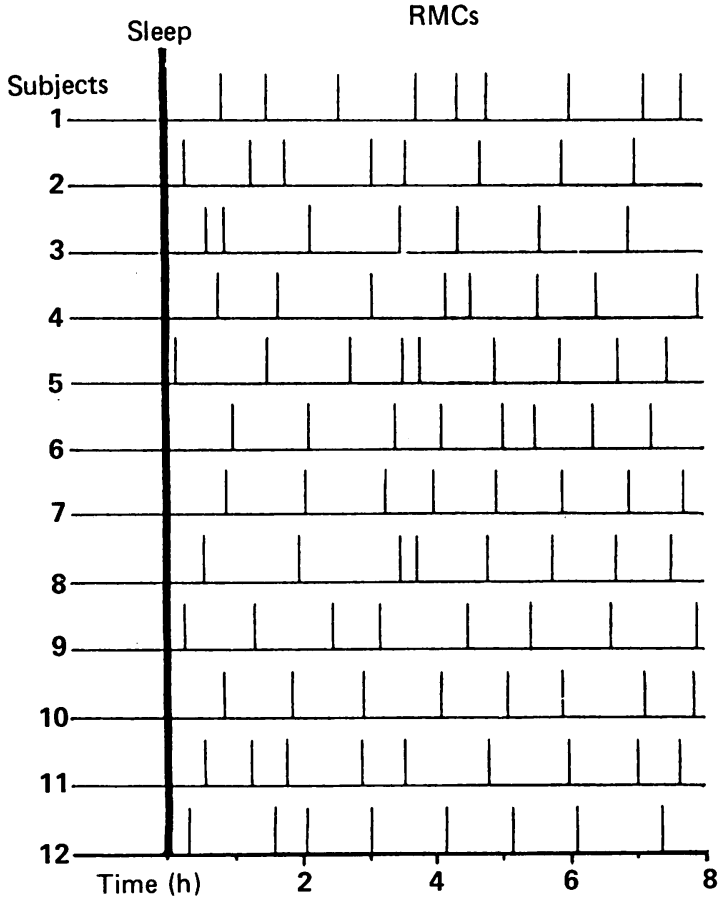

Fig. 4 Distribution of RMCs during sleep in all subjects. Each horizontal line represents a subject and each vertical bar represents a $R M C$.

ANAL CANAL

The anal canal showed bursts of contractions which were less frequent than RMCs and were not always temporally related (Fig. 3). The anal canal also exhibited powerful isolated contractions. These did not seem to be related to isolated rectal contractions.

Table Ultradian variation in rectal motility

\begin{tabular}{|c|c|c|c|c|c|}
\hline \multirow[b]{2}{*}{ Subject } & \multicolumn{2}{|c|}{$\begin{array}{l}R M C \text { periodicity } \\
\text { (mean minutes) }\end{array}$} & \multirow[b]{2}{*}{$\begin{array}{l}\text { Disruption } \\
\text { by food }\end{array}$} & \multirow{2}{*}{$\begin{array}{l}\text { Frequency of } \\
\text { contraction } \\
\text { per min }\end{array}$} & \multirow[b]{2}{*}{$\begin{array}{l}\text { Peak } \\
\text { amplitude } \\
\text { (mmHg) }\end{array}$} \\
\hline & Day & $\begin{array}{l}\text { Night } \\
\text { (sleep) }\end{array}$ & & & \\
\hline 1 & 92 & 48 & Yes & $2 \cdot 5$ & 60 \\
\hline 2 & 86 & 55 & Yes & $2 \cdot 0$ & 45 \\
\hline 3 & 101 & 61 & Yes & $3 \cdot 0$ & 50 \\
\hline 4 & 94 & 66 & Yes & $3 \cdot 0$ & 65 \\
\hline 5 & 96 & 49 & Yes & $3 \cdot 0$ & 52 \\
\hline 6 & 105 & 58 & Yes & $3 \cdot 0$ & 38 \\
\hline 7 & 89 & 58 & Yes & $3 \cdot 0$ & 60 \\
\hline 8 & 92 & 55 & Yes & $2 \cdot 0$ & 50 \\
\hline 9 & 84 & 60 & Yes & $3 \cdot 0$ & 55 \\
\hline 10 & 90 & 50 & Yes & $2 \cdot 5$ & 40 \\
\hline 11 & 98 & 48 & Yes & $3 \cdot 0$ & 60 \\
\hline 12 & 82 & 62 & Yes & $3 \cdot 0$ & 35 \\
\hline \multicolumn{2}{|c|}{ Mean (SEM) } & \multicolumn{2}{|c|}{$\begin{array}{l}92.42(1.98) \\
55.83(1.74)\end{array}$} & & \\
\hline
\end{tabular}

Day $v$ night $\mathrm{p}<0 \cdot 001$. 


\section{Discussion}

This method not only allows for evaluation of variations in contractile patterns of anorectal motility over a 24 hour period but also makes it possible to assess the role of various reflex mechanisms that are considered important in maintaining continence.

Since Szurszewski's ${ }^{1}$ description of a myoelectric complex migrating over the entire length of the canine small bowel, many studies on the identification and analysis of periodic activity have concentrated on the human small intestine; the colon and the anorectum have been relatively neglected. Anorectal motility is conventionally measured in a laboratory setting and with the aid of applied stimuli such as a balloon distension, infusion of air, or traction on the puborectalis. ${ }^{115} 16$ Using these techniques, the rectum has been reported to exhibit contractile activity with a frequency of two to three cycles per minute in response to rectal filling or distension. Such studies do not measure spontaneous activity, but the anorectal response to a stimulus, and are inappropriate for the detection of spontaneous periodic activity. In contrast, in the present study, we recorded anorectal contractile activity in the subjects' own environment for a prolonged period. In our study, the rectum showed cyclic activity with a periodicity of $92(1.9)$ minutes. This was not associated with either a feeling of rectal fullness or urge to defecate. Moreover, this type of activity, like the small bowel, was more regular during sleep. It is therefore unlikely that these periods of sustained regular activity are either induced by or associated with rectal filling. These clusters of sustained regular activity in the rectum closely resemble phase III activity in the small intestine, but lack the preceding phase of irregular contractions (phase II). Nevertheless, the term 'rectal motor complex' (RMC) seems appropriate. Rectal motor complexes also resemble MMCs in that they are more regular at night with a significantly shorter cycle length. As we only used one sensor in the rectum, we can not comment on propagation of these RMCs in the rectum or the anal canal. Narducci et $\mathrm{ll}^{17}$ recorded colonic motor activity for prolonged periods of time in human subjects and did not find any evidence of periodic activity in the colon. In view of their findings it is possible that periodic motor activity only exists distal to the rectosigmoid junction.

In contrast, the anal canal did not show any evidence of periodic motor activity. This may either reflect the absence of periodic activity throughout the anal canal or simply the fact that one recording sensor positioned in the mid anal canal is not able to record periodic activity in the upper anal canal. It is possible that phasic rectal motor activity ends in the upper anal canal and on those occasions when bursts of contractions related to RMCs were recorded, this may have been caused by orad displacement of the sensor. Further studies with multiple sensors in the anal canal will be required to clarify this issue.

In conclusion, we have shown that the anorectum, like the upper gastrointestinal tract, exhibits periodic motor activity. Because it is more marked during sleep, it seems likely that anorectal periodic activity is, like the proximal migrating motor complex, a function of intrinsic rather than extrinsic innervation. It also remains to be determined whether rectal motor complexes show synchrony with the MMC, or, unlike the MMC, with the REM/non-REM CNS biorhythm. Of greater clinical relevance is the possibility that minimally invasive techniques for the detection of RMCs might be useful in the assessment of anorectal intrinsic neural integrity in patients with anorectal dysfunction.

\section{References}

1 Szurszewski JH. A migrating electric complex of the canine small intestine. Am J Physiol 1969; 217: 1757-63.

2 Vantrappen G, Janssens J, Hellemans J, Ghoos Y. The interdigestive motor complex of normal subjects and patients with bacterial overgrowth of the small intestine. J Clin Invest 1977; 22: 117-24.

3 Flackenstein P. Migrating electrical spike activity in the fasting human small intestine. Am J Dig Dis 1978; 23: 239-47.

4 Ruckebusch Y, Pairet M, Becht JL. Origin and characteristics of migrating myoelectric complex in rabbits. Dig Dis Sci 1985; 30: 742-8.

5 Galligan JJ, Costa M, Furness JB. Gastrointestinal myoelectric activity in conscious guinea pigs. Am J Physiol 1985; 249: 92-9.

6 Kellow JE, Borody TJ, Phillips SF, Tucker RL, Haddad AC. Human interdigestive motility: variations in patterns from esophagus to colon. Gastroenterology 1986; 91: 386-95.

7 Loening-Baucke VA. Anorectal manometry: experience with strain gauge pressure transducers for the diagnosis of Hirschprung's disease. J Paediatr Surg 1983; 18: $595-600$.

8 Dent JA. A new technique for continuous sphincter pressure measurement. Gastroenterology 1976; 71: 263-7.

9 Harris LD, Pope CE. Squeeze vs resistance: an evaluation of the mechanism of sphincter competence. J Clin Invest 1964; 43: 2272-8.

10 Bubrick MP, Godec CJ, Cass AJ. Functional evaluation of the rectal ampulla with ampullometrogram. $J R$ Soc Med 1980; 73: 234-7.

11 Scharli AF, Keiswetter WB. Defecation and continence: some new concepts. Dis Colon Rectum 1970; 13: 81-107.

12 Whitehead WE, Engel BT, Schuster MM. Irritable bowel syndrome: physiological and psychological differences between diarrhoea predominant and constipation predominant patients. Dig Dis Sci 1980; 25: 404-13. 
13 Browning C, Valori RM, Wingate DL. A new pressuresensitive ingestible radio-telemetric capsule. Lancet 1981; ii: 504-5.

14 Browning C, Valori RM, Wingate DL. Receiving, decoding and noise limiting systems for a new pressuresensitive ingestible radio-telemetric capsule. $J$ Biomed Eng 1983; 5: 262-6.
15 Connell AM. The motility of the pelvic colon. Gut 1961; 2: $175-86$.

16 Kerremans R. Morphological and physiological aspects of anal continence. Brussels: Arscia, 1969.

17 Narducci F, Bassotti G, Gabburi M, Morelli A. Twenty four hour manometric recording of colonic motor activity in healthy man. Gut 1987; 28 : 17-25. 